\title{
Pancreatic Calcification in Primary Hyperparathyroidism
}

Roma Pradhan, Sushil K Gupta, Zafar Neyaz, Amit Agarwal

How to cite this article: Pradhan R, Gupta SK, Neyaz Z, Agarwal A. Pancreatic Calcification in Primary Hyperparathyroidism. World J Endoc Surg 2013;5(3):89.

\section{Source of support $\mathrm{Nil}$}

\section{Conflict of interest None}

We present a case of 38-year-old male who presented with history of recurrent renal stones since 15 years, with occasional upper abdominal discomfort without any acute attack of pancreatitis. X-ray kidney urinary bladder (K UB) showed multiple pancreatic calcification (Fig. 1). A diagnosis of primary hyperparathyroidism (PHPT) was made [raised ionized calcium levels and raised intact parathyroid hormone (iPTH)]. Localization studies revealed right inferior parathyroid adenoma [(SESTAM IBI scan and ultrasonography (USG) neck]. Endoscopic (chest wall approach) parathyroidectomy was successfully performed. Intraoperative parathyroid hormone (IOPTH) show ed curative fall. Postoperatively, patient required calcium and vitamin D supplements for hungry bone syndrome.

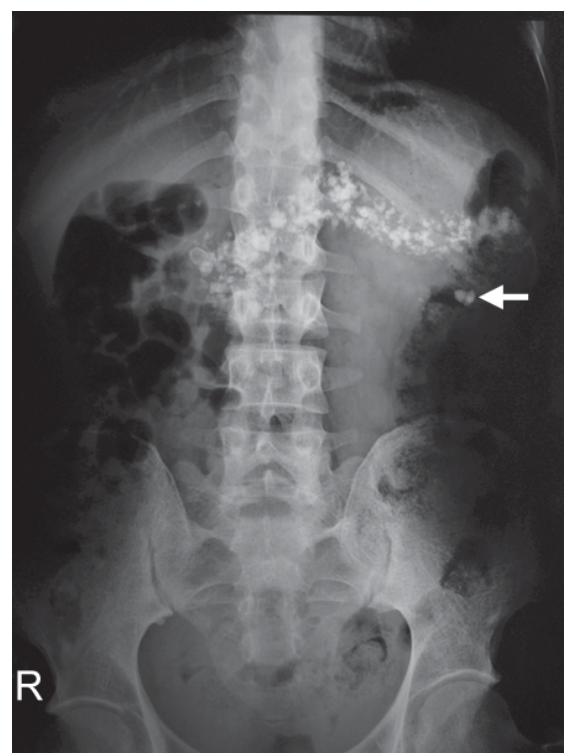

Fig. 1: Multiple coarse calcific foci seen at the level of L1, L2 vertebrae oriented transversely crossing midline following the pancreatic contour suggestive of pancreatic calcification. Calcific foci seen over left renal fossa likely left renal calculi (arrow)

\section{ABOUT THE AUTHORS}

\section{Roma Pradhan}

Senior Resident, Department of Endocrine Surgery, Sanjay Gandhi Postgraduate Institute of M edical Sciences, Lucknow, Uttar Pradesh, India

\section{Sushil K Gupta}

Professor, D epartment of Endocrinology, Sanjay Gandhi Postgraduate Institute of M edical Sciences, L ucknow, U ttar Pradesh, India

\section{Zafar Neyaz}

A dditional Professor, Department of Radiodiagnosis, Sanjay Gandhi Postgraduate Institute of M edical Sciences, Lucknow, Uttar Pradesh, India Amit Agarwal (Corresponding Author)

Professor, Department of Endocrine Surgery, Sanjay Gandhi Postgraduate Institute of M edical Sciences, Lucknow, Uttar Pradesh, India Phone: 8004904645, e-mail: amit@ sgpgi.ac.in 